\title{
Statistical parameters of Bhuj earthquake sequence of January 26th, 2001
}

\author{
M A Shaik and Sanjay SRivastava \\ Seismology Unit, Engineering Geology Division, Gujarat Engineering Research Institute, Race Course, \\ Vadodara 390007
}

\begin{abstract}
An intraplate earthquake of magnitude $\left(M_{c}\right) 6.9$ (Anon 2001a) struck Bhuj and the adjoining region of Kachchh in Gujarat on January 26th, 2001 at about 0316 hrs (GMT) and was followed by a number of aftershocks. The epicentre of this earthquake was located at $23.4^{\circ} \mathrm{N}$ and $70.28^{\circ} \mathrm{E}$ close to the Kachchh mainland fault. The intensity observed around the epicenter was X on the MSK scale.

A study of 531 aftershocks, in the magnitude range of 3.0-5.7, recorded at Vadodara Seismological Observatory till March 31st, 2001 has been carried out and various statistical parameters calculated. The total energy released during the study period is calculated to be $8.2 \times 10^{14}$ joule. Sudden occurrence of the main shock without any foreshock in the same tectonic system is a unique feature of this sequence. The $b$-value (0.86), value of $M_{0}-M_{1}(1.2)$, high $M_{1} / M_{0}(0.89)$ and high value of the decay constant $h(0.91)$, all support the tectonic origin of the present study.
\end{abstract}

\section{Introduction}

The Bhuj earthquake of January 26th, $2001\left(M_{c}=\right.$ 6.9) took a heavy toll of human lives, exceeding 17000 (Anon 2001b). The damage was maximum in Bhachau, Bhuj, Anjar, Gandhidham and Rapar talukas of Kachchh district and of relatively lesser extent in parts of Saurashtra and parts of north Gujarat. Loss of human lives and damage to buildings have also been reported from far off places like Ahmedabad, Surat, Navsari, parts of Rajasthan and Hyderabad (Sind, Pakistan). The liquefaction features such as sand blows, lateral spreads etc. in some areas were spectacular expressions of the effects of ground shaking (Anon 2001b). Some fluctuations in the ground water table and ground water quality were also reported in the initial days during the post earthquake period. The main shock was followed by many aftershocks which were recorded at various seismological observatories of the state seismic networks.

Some microearthquake activities have also been noticed in the adjoining tectonic features before the Bhuj earthquake of January 26th, 2001. These are (1) Bhavnagar micro earthquake sequence of August-September, 2000 ( $M=3.2-4.4)$; (2) Khamba (Amreli) earthquakes on August 13th, $2000(M=4.6$ and $M=3.3)$; (3) Khavda earthquake on December 24th, 2000 (Island Belt fault, $M=4.4)$ (Anon 2000).

In the present work, a total of 531 aftershocks in the magnitude range of 3.0-5.7, recorded at Vadodara seismological observatory by photographic type electromagnetic seismograph till March 31st, 2001, are analysed for various statistical parameters.

\section{The foreshock-aftershock pattern}

A significant feature of this sequence is that there is no foreshock prior to the main shock. However 531 aftershocks were recorded at Vadodara observatory in the magnitude range of 3.0-5.7. Only a few major earthquakes in other parts of the world have had such a pattern.

The pattern of the daily frequency distribution of these shocks fits into type-1 of Mogi's model

Keywords. Foreshock; aftershock; $b$-value; decay constant; energy; tectonic stress. 


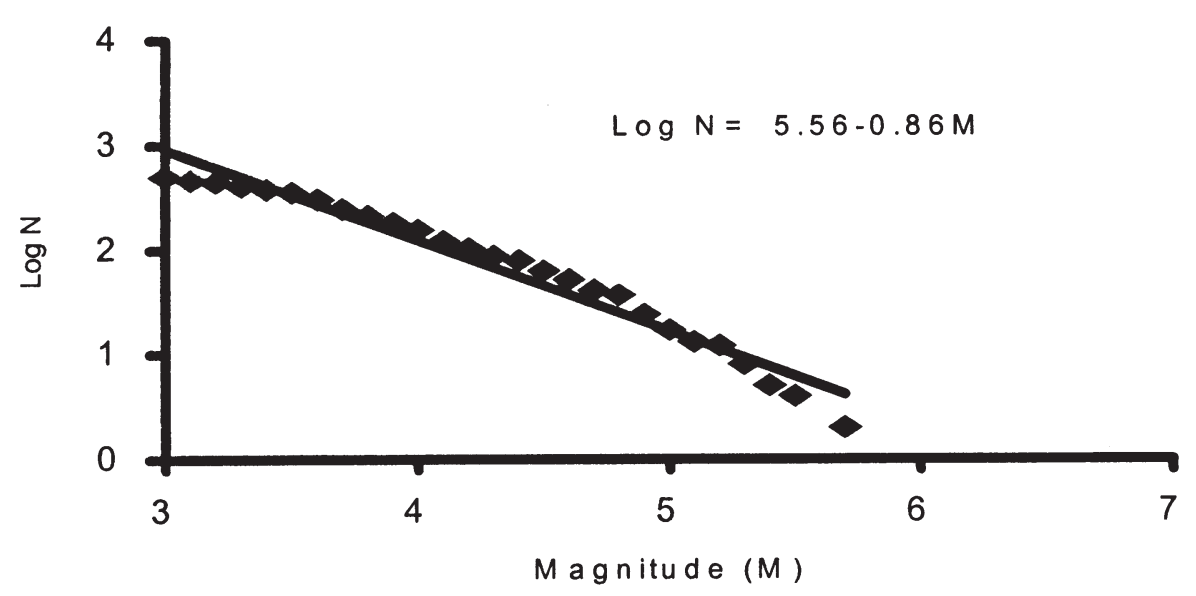

Figure 1. Frequency-magnitude relationship.

(Mogi 1985) which is for the homogeneous material and uniform applied stress. Broach earthquake sequence of March 23rd, $1970(M=5.7)$ is another typical example of Mogi's type-1 model in Gujarat (Gupta 1976).

\section{Frequency-magnitude relationship}

The frequency-magnitude distribution of earthquake is well expressed by the Gutenberg-Richter relation (Richter 1958)

$$
\log N=a-b M
$$

where $N$ is the number of shocks of magnitude $M$ and more, $a$ and $b$ are constants. This relationship shows that the number of earthquakes declines logarithmically with the increase in the magnitude. The extent of this decline is expressed by the $b$ value which is normally close to 1 (Mogi 1985). Studies of Mogi (1963b) and Scholz (1968) reveal that the $b$-value depends on the percentage of existing stress to the final breaking stress within the fault. Also it depends on the mechanical heterogeneity of the rock mass and increases with the increase in the heterogeneity.

Fitting equation (1) to the present aftershock sequence by using the graphical approach gives $a$ and $b$ as 5.56 and 0.86 respectively.

Agrawal (1991) states that tectonic earthquakes are characterised by the $b$-value from 0.5 to 1.5 and are more frequently around 1.0, which is observed in the present study.

\section{Relationship between the magnitudes of the main shock and the largest aftershock}

The difference between the magnitudes of the main shock and the largest aftershock depends on the stress condition and heterogeneity of the rock mass. According to Bath's (1965) law for large normal shallow earthquakes, the difference between magnitudes of the main shock $\left(M_{0}\right)$ and the largest aftershock $\left(M_{1}\right)$ is 1.2 i.e.,

$$
M_{0}-M_{1}=1.2 .
$$

A similar result was obtained by Papazachos (1971) for 216 aftershock sequences with $M_{0} \geq 5$ which occurred in Greece. The same law holds good for the Bhuj aftershocks sequence also as the values of the magnitude of the main shock and the largest aftershock are 6.9 and 5.7 .

The ratio of these magnitudes $\left(M_{1} / M_{0}\right)$ is 0.89 which is quite high. Similar observations were made by several workers for the California earthquakes sequence (Gupta 1976).

\section{Decay trend of the activity}

Utsu's (1969) time distribution of aftershocks given by the inverse power relation

$$
n(t)=c t^{-h}
$$

is used to calculate decay constant $h$ and unit time $t$ is taken as one day. Figure 2 presents the decay pattern of the aftershocks. The relationship found is

$$
n(t)=86.22 t^{-0.91} .
$$

The decay constant $h$ is found to be 0.91 which is very high. As per Reid's elastic rebound theory, the basic physical process involved in the generation of earthquakes is the slow building up and rapid release of tectonic stress in a cyclic process. 


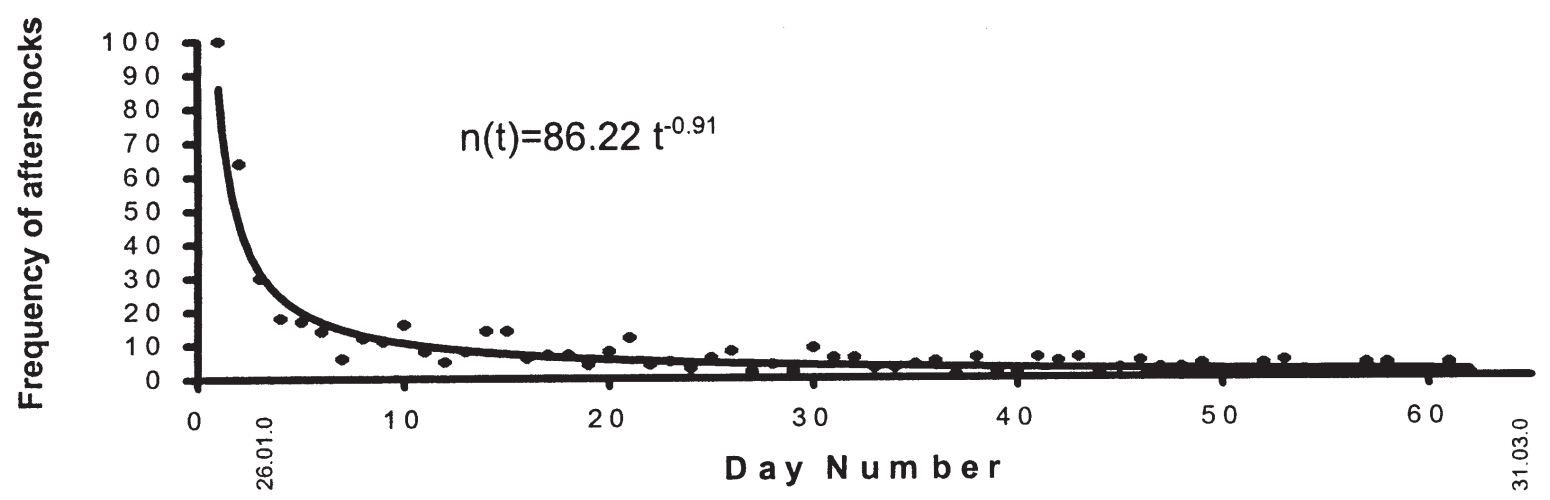

Figure 2. Decay curve for Bhuj earthquake sequence.

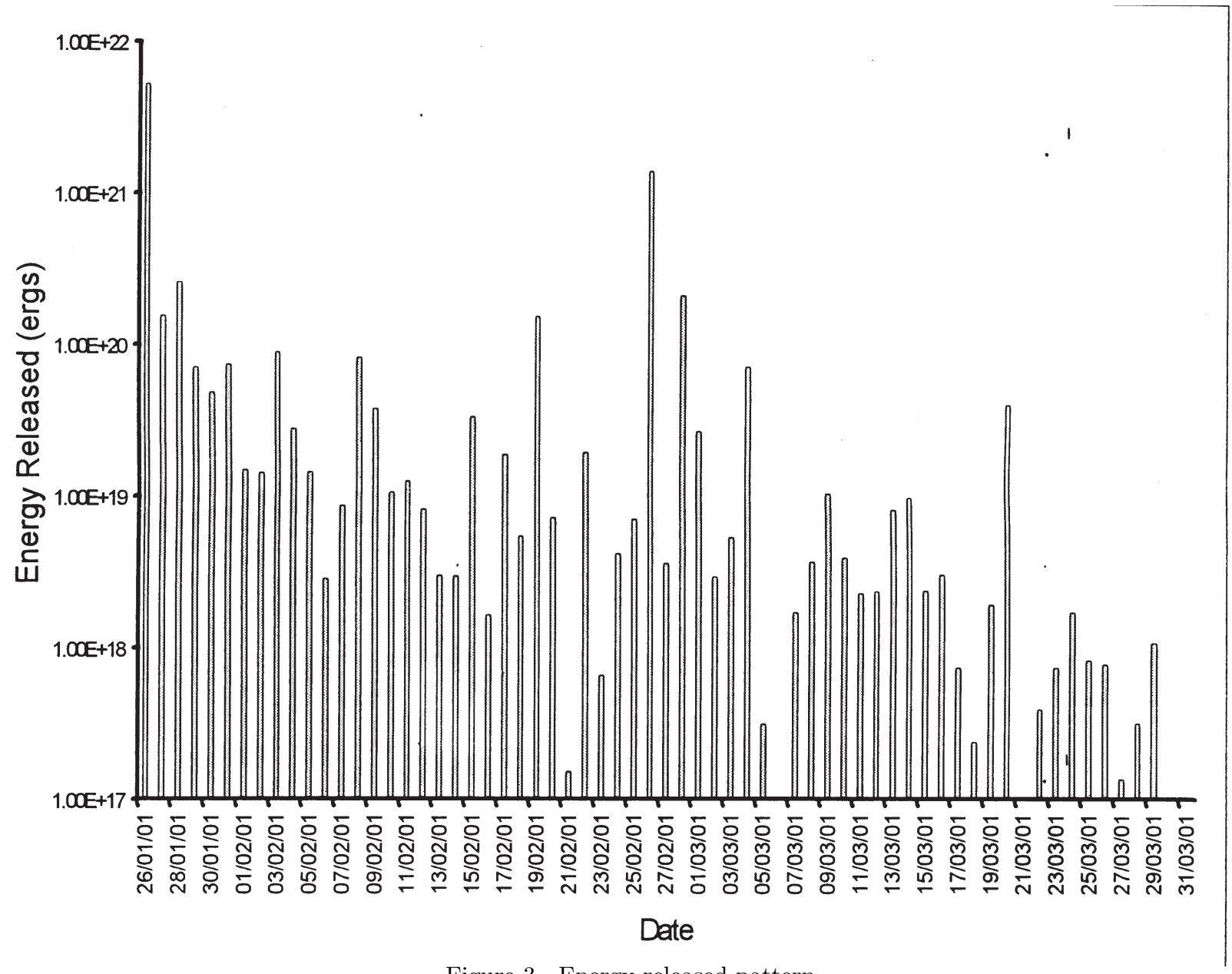

Figure 3. Energy released pattern.

The close observation of the decay curve (figure 2) reveals that though the general decay trend is exponential, the plotted points indicate the number of aftershocks occurring in a sinusoidal pattern which supports the release of tectonic stress in a cyclic process.

\section{Energy release pattern}

The energy released during this sequence is calculated by using the relation

$$
\log (E)=13.8+1.23 M \text {. }
$$


Figure 3 presents the day-wise energy release pattern. Total energy released is calculated to be in the order of $8.2 \times 10^{14}$ joule during the study period.

\section{Conclusions}

Various statistical parameters calculated for the Bhuj earthquake sequence present some attractive features:

- The sudden occurrence of the main shock without even a single foreshock in the same tectonic system is the unique feature of this sequence. This may be due to relatively homogeneous subsurface with compact rock mass.

- The $b$-value (0.86) approaching unity, value of $M_{0}-M_{1}(1.2)$ and high value of the ratio $M_{1} / M_{0}$ (0.89) supports the normal tectonic origin of the present activity.

- The high value of decay constant $h(0.91)$ is indicative of the rapid decay of earthquake activity having tectonic origin.

- Total energy released is calculated to be $8.2 \times$ $10^{14}$ joule.

\section{Acknowledgements}

The authors are grateful to Sri V S Bhramabhatt, Chief Engineer and Director, GERI, Vadodara for constant encouragement. The authors are indebted to Sri C S Shah, Superintending Engineer (Geology), CDO, Gandhinagar for making useful suggestions. Thanks are also due to Sri P S Lattoo, Geologist(Sr), GERI, Vadodara for useful comments.

\section{References}

Agrawal P N 1991 Engineering Seismology (New Delhi: Oxford \& IBH Publishing Co Pvt Ltd)
Anon 1971 Gazetteer of India: Kutch (Kachchh) District

Anon 2000 Special Reports of Gujarat Engineering Research Institute, Govt. of Gujarat; Narmada, Water Resources \& Water Supply Dept., Vadodara, India (unpublished)

Anon 2001a Bhuj earthquake of January 26, 2001 (a consolidated preliminary report); March, 2001; India Meteorological Department; Govt. of India, New Delhi.

Anon 2001b A brief note on Bhuj earthquake sequence and damages to earth dams; Govt. of Gujarat; Narmada, Water Resources \& Water Supply Dept., Vadodara, India (unpublished)

Bath M 1965 Lateral inhomogeneities in the upper mantle; Tectonophysics 2 483-514

Gupta H K 1976 Dam \& Earthquakes (Amsterdam: Elsevier Scientific Publishing Company)

Iyer H M 1986 Earthquake prediction - present status; Proceeding of Symposium, Poona University, July 1986

Mogi K 1963B Some discussions on aftershocks, foreshocks and earthquake swarms - the fracture of a semi infinite body caused by an inner stress origin and its relation to the earthquake phenomena; Bull. Earthquake Res. Inst. 41 615-658

Mogi 1985 Earthquake Prediction (Tokyo: Academic Press)

Papazachos B C 1971 Aftershock activity and aftershock risk in the area of Greece; Ann. Geofis (Rome) 24439 456

Richter Charles F 1958 Elementary Seismology (San Francisco; California: W.H. Freeman \& Co, Inc.)

Scholz C H 1968 Micro fracturing and the inelastic deformation of rock in compression; J Geophysics Res. 73 14171432

Srivastava, Sanjay et al 1997 Present status of seismicity of Gujarat, Vayumandal, India Meteorological Department, Govt. of India, New Delhi. January-June 1997, 32-39

Srivastava, Sanjay et al 1989 Earthquake swarm activity in south Gujarat; Mausam, India Meteorological Department; Govt. of India, New Delhi; 42, 1, 89-98

Tandon A N 1992 Seismicity in India - An overview upto 1970; Current Science Special Issue

Utsu T 1969 Aftershock and earthquake statistics, I. Some parameters which characterize an aftershock sequence and their interrelations; J. Fac. Sci. Hokkaido Univ., Ser. 7 (Geophysics) 3 129-195 